resonance, curves, and mode shapes for these periods. In addition, torsional modes of vibration have been established together with the centres of rotation. It is also possible to obtain viscous damping factors from the shapes of the resonance curves.

Seismologists hope that the work of recording strong earthquake motion with the related activities of questionnaire and vibration programmes will continue, so that, like statistics on precipitation, wind, temperature and tides, reliable data on ground motions will be available. In the meantime, it is hoped to have accumulated sufficient material in two years to warrant the publication of another volume of papers.

\section{Phosphorus in Soil}

SINCE it became apparent many years ago that a determination of the total nutrients in the soil gave little indication of what would become available to the plant during a growing season, soil chemists have devised numerous relatively simple laboratory techniques to assess availability. Based on convenience and local experience, these methods have played a useful part in assisting the farmer with his fertilizer programme, but inevitable difficulties arose in comparing the results of work in different areas. Soil phosphorus has been a par. ticularly complex problem because crop responses to applied phosphorus have varied widely, not only between soils but also between seasons, and correlations of laboratory and field data have been burdened by anomalies. It was fitting, therefore, that a serious attempt should be made to examine techniques and experimental results from a large number of soils. At a conference in October 1962, organized by the National Agricultural Advisory Service, fifteen papers covering various aspects of the subject were presented and discussed, and five syndicates considered and reported on several specific questions confronting the adviser: (a) the concept of intensity and capacity factors; $(b)$ the possibility of selecting one routine method for determining available phosphorus; (c) the mode of expressing soil phosphorus; (d) the classification of soil phosphorus figures; and $(e)$ the factors concerned in the interpretation of the results. A full record of the proceedings has now been published in Soil Phosphorus (Ministry of Agriculture, Fisheries and Food. Technical Bulletin No. 13. Pp. v +159. London: H.M.S.O., 1965. 37s. 6d. net). It is a most valuable guide to the present position with respect to the measurement of fertility levels, the difficulty of assessing the influence of soil organic matter, the grouping of crops in manuring recommendations and the kind of investigations still required to improve the advice given to farmers.

\section{Water in Living Systems}

Forms of Water in Biologic Systems comprises a series of papers delivered at a conference of the New York Academy of Sciences in October 1964 (Ann. N.Y. Acad. Sci., 125. Article 2. By H. J. Berendsen and 39 other authors. Pp. 249-772. New York: New York Academy of Seiences, 1965. 10 dollars). Only a month before, a similar British symposium, organized by the Society for Experimental Biology, was held at Swansea, under the general title "The State and Movement of Water in living Organisms". Both these symposia have now appeared in print, and they testify to the considerable interest which exists at the present moment in the properties of the fluid which is undoubtedly the most important single chemical compound in living things. Inevitably the two symposia will be compared. What emerges from the comparison is that there is little overlap, for whereas the Swansea symposium was oriented towards what might be called the larger-scale aspects of plant and animal water relations (though it deals also with the theoretical and physical background), the New York symposium is concerned rather more with physico- chemical and macromolecular aspects of the subject. Particularly interesting is a contribution from Prof. Fernandez Moran appearing in the discussion at the end, in which he outlines some exciting developments in the direction of high-resolution electron microscopy, at liquid helium temperatures, of structures involving water on the molecular level. This seems to indicate a line of advance from which much may be expected.

\section{Document Preservation}

THE preservation of paper is a recognized necessitysometimes, it may be thought, an unfortunate one. Micro-filming, the obvious solution to the problem of storage, has some practical drawbacks. Much thought has therefore been given to the subject, but much of it is pointless unless the resistance of a paper to ageing can be forecast numerically.

In 1928 the National Bureau of Standards, Washington, D.C., evolved such a test. It was based on the determination of the decrease in folding resistance after heating for $72 \mathrm{~h}$ at $105^{\circ} \pm 2^{\circ} \mathrm{C}$. As a result of evaluations of stored papers at intervals during the following years ${ }^{1}$, it is considered that the conditions of this test are equivalent to natural ageing for 25 years under normal room storage conditions. On the relatively short view of a century or so, a recent article entitled "Archives Document Preservation" by Raff, Herrick and Adams of the Washington State University, Pullman, Washington ${ }^{2}$, is of particular interest. These workers started with the accepted fact that acidity found in paper on storage is the principal cause of deterioration. Treatment with calcium and magnesium bicarbonates is a recognized antidote. The authors carry this principle a stage further by using the alkali salts of organic polyacids; on impregnation with this mixture, a paper will be both neutralized by the buffering effect and also reinforced. Preliminary experiments justified these expectations, but showed the necessity for the addition of a plasticizer in order to improve the folding resistance.

Such papers, when subjected to the standard accelerating ageing test, showed little or no decrease in $p H$ value or folding resistance; the wet strength was actually increased by the test. The quantitative significance of these results must be assessed with caution, however, since the accepted ageing test referred to above is based on paper fibres alone and may not necessarily apply to paper treated by the authors' method.

${ }^{1}$ Wilson, W. K., Harvey, J. L., Mandel, J., and Workman, T., J. Tech. Assoc. Pulp and Paper Indust., 38, 543 (i955).

2 Raff, R. A. V., Herrick, I. W., and Adams, M. F., Northwest Science, 40, $17(1966)$.

\section{Medical Sciences at Toronto}

Tне University of Toronto has completed plans for its new Medical Sciences building, the largest and most complex structure planned for any Canadian university. By this means Toronto hopes to become one of the largest medical schools in North Americe, increasing its class to 250 a year by the time the main facilities are completed in 1969 .

The complex of buildings will comprise a teaching block of five floors and a research tower of eight with an adjacent three-storey auditorium; the cost of the building is estimated at $\mathbf{2 9 . 5}$ million dollars and equipment will cost an additional 6.5 million dollars. The University plans to break ground this June, to complete the teaching and research blocks by September 1969, and to finish the auditorium building the following year.

The stimulus for the project was a committee report in May 1964 which said that "inadequacies of space have frustrated the development of research and the increasing demands of administrative duties and teaching have markedly reduced the effectiveness of the existing staff and hindered the acquisition of new staff of high calibre". 